\title{
EVALUATION OF NEW GEOPHYSICAL TOOLS FOR INVESTIGATION OF A LANDFILL, CAMP ROBERTS, CALIFORNIA
}

\author{
W.E. Doll and T.J. Gamey, Oak Ridge National Laboratory, Oak Ridge, TN \\ J.E. Nyquist, Temple University, Philadelphia, PA \\ W. Mandell, U. S. Army Environmental Center, MD \\ D. Groom, Geometrics Inc., San Jose, CA \\ S. Rohdewald, Intelligent Resources Inc., Vancouver, BC, Canada
}

\begin{abstract}
Characterization of material changes with depth (profiles) in many landfill sites can be problematic for some conventional geophysical methods. Localized anomalies within the landfill can complicate mapping of underlying layers, and layered-model techniques are inappropriate for imaging laterally discontinuous landfills.

Recently-developed geophysical hardware and software tools provide the opportunity to image the vertical structure of a landfill and its geologic setting. In May, 2000 a sequence of geophysical data sets were acquired at a landfill site at Camp Roberts, CA to test the benefits of new hardware and software for characterizing the three-dimensional boundaries of the landfill and the geologic setting. Conventional magnetic and electromagnetic measurements provided a backdrop for these new methods. A Geometrics G-858 magnetic gradiometer equipped with a real-time GPS positioning system was used to map the areal extent of the landfill.

Resistivity, seismic refraction, and electromagnetic data were acquired along profile lines to characterize the vertical extent of the landfill and geology. Seismic refraction data were processed with conventional time-delay methods, and with newer tomographic methods. The multielectrode resistivity data were compared with data acquired with the capacitively-coupled OhmMapper system

The landfill boundaries that are defined in map view by the magnetic data are supported in profile by the seismic refraction data and multielectrode resistivity data. The seismic data are most effective in identifying trench locations when a tomographic inversion is used, instead of a conventional delay-time approach to interpretation. This shows a localized high-velocity zone that coincides with the trench boundaries that are defined by the magnetic data. The multielectrode resistivity data show a disruption of layering where trenching has occurred.

Both the seismic data and the multielectrode resistivity data provide evidence that the shallow geology is laterally discontinuous and heterogeneous. The high electrical conductivity of the near surface imposed limitations on the penetration depth of both the OhmMapper and multielectrode resistivity systems. The multielectrode system was better suited for penetrating this zone than was the OhmMapper.
\end{abstract}




\section{Introduction}

In May 2000, magnetic, electromagnetic, electrical, and seismic geophysical data were acquired at the Camp Roberts Sanitary Landfill, San Luis Obispo County, California. The primary purpose of the investigation was to determine whether the old and new landfills have distinct boundaries, and if they overlap. In addition, recently developed methods were evaluated for depth profiling within the landfill.

Camp Roberts, built in 1941-1942, is located about 35 miles north of San Luis Obispo, California, and consists of high plains, rolling hills, stream valleys totaling more than 42,000 acres. Sparse live oaks are found over much of the facility. The Camp Roberts solid waste disposal facilities include a permitted landfill and at least five waste disposal areas that were closed before the State and County landfill permitting programs came into effect (Geosystems Consultants Inc., 1992). The 14.3-acre permitted landfill consists of an active north unit and a closed (inactive) south unit (Figure 1).

The five closed waste disposal areas are all south of the permitted landfill. They consist of a small canyon fill, referred to as the T-1/T-2 disposal area (labeled as "Waste Disposal Area" in Figure 1) and four trench fills referred to as trenches T-3 through T-6 (located south of the area shown in Figure 1). This portion of the landfill was developed during peak activities during World War II and the Korean War. Several lysimeter and ground water monitoring wells are located within the landfill area.

The surficial geologic map for Camp Roberts (Environmental Science Associates, Inc, 1989) indicates that the rocks exposed at the surface are Cenezoic non-marine sedimentary deposits. Clays and clastic sediments (silts, sands, gravels, and mixed grain-size) are reported in well logs from the top $200 \mathrm{ft}$ (Smith, Gardner, and Dunne, Inc., 1989). Other well logging reports use terminology for lithified rocks that would be derived from each sediment type (e.g. siltstone, sandstone, conglomerate; EMCON Associates, 1990). We infer that the subsurface consists of weathered sedimentary rocks or uncemented alluvial materials. The presence of gravels or conglomerates indicates some degree of stream deposition that would result in a heterogeneous subsurface. The lack of stratigraphic correlation from one well to another provides further evidence of discontinuous alluvial lithologies in the subsurface.

Water table elevations have been measured in several monitoring wells at the site. These elevations range from 570 to $615 \mathrm{ft}$, where surface elevations range from 700 to $830 \mathrm{ft}$. A contour map of these data (Geosystem Consultants Inc, 1998, Fig 4) shows a steep northward gradient extending downward from the T-1/T-2 trench area toward the active landfill. The gradient shows the water table dropping more than $40 \mathrm{ft}$ where topography rises $60 \mathrm{ft}$. Bedrock depths at the site are unknown. 
Figure 1 is a total magnetic gradient (analytic signal) map of the area of investigation with known landfill locations, wells, and geophysical profile lines overlain. EM-61 electromagnetic data were acquired over a $300-\mathrm{ft} X 300$-ft quadrant in the southeast portion of this grid to compare with the G-858 magnetic data. Both seismic refraction and multielectrode resistivity data were acquired along the profile lines (Fig. 1). Electromagnetic data were acquired with the Geometrics OhmMapper system in a southeast quadrant and along the A and B profile lines for comparison with the multielectrode and seismic results.

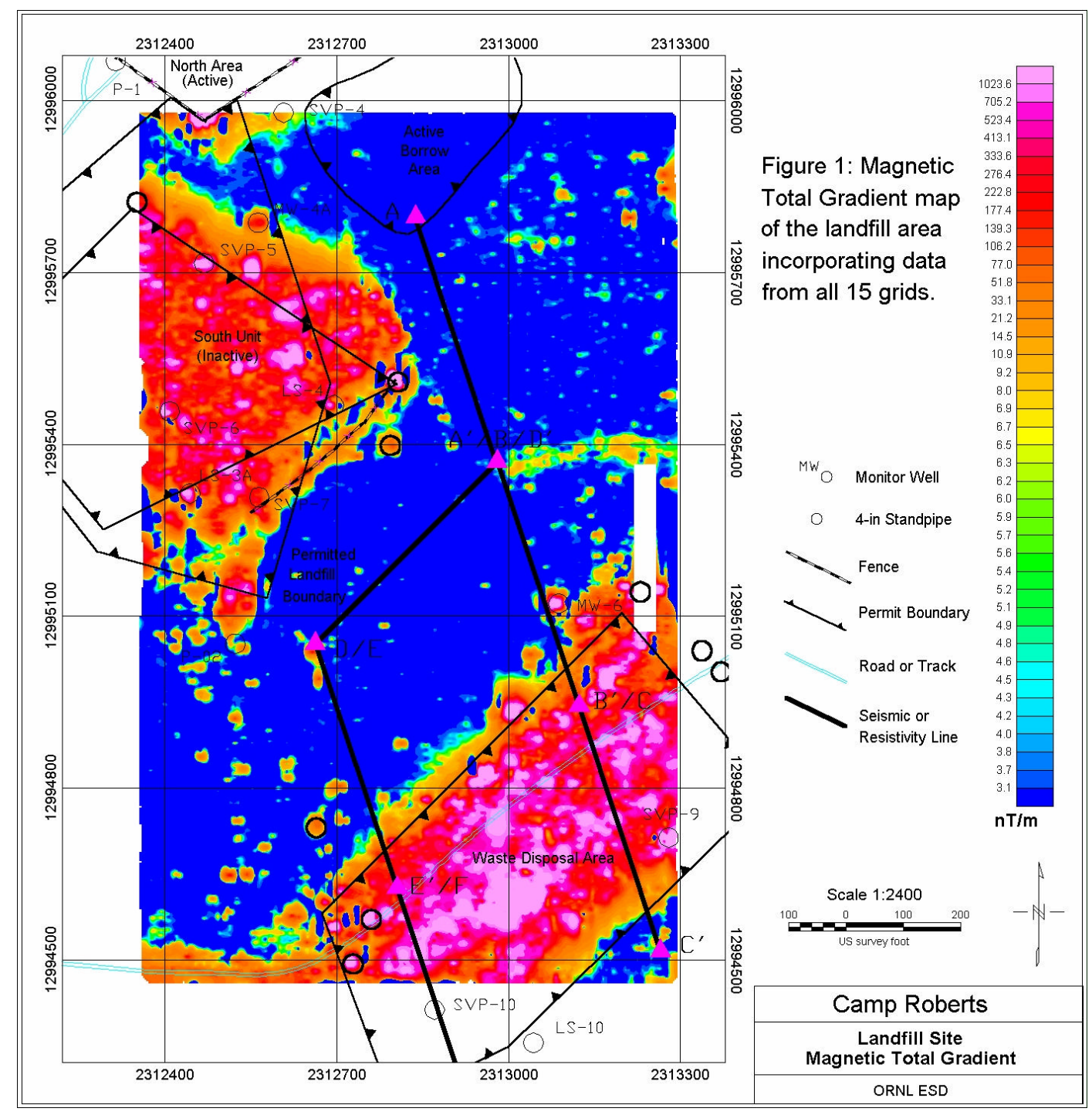

Figure 1. Magnetic Total Gradient map (analytic signal) of the landfill area incorporating data from all 15 grids. Various land permit areas and geophysical survey lines shown in black. 


\section{Magnetometer Survey}

The Geometrics G-858 magnetic gradiometer, equipped with an AG-132 GPS positioning system with Omnistar differential correction was used for this survey. The G-858 was operated in vertical magnetic gradient mode with a $1.6 \mathrm{ft}$ separation of magnetometers. Data processing steps included registration of lines, conversion to Geosoft data format, integration of data from 15 quadrants into a single file, editing, gridding, and contouring. No filtering of the data was required, although several data dropouts were removed. The field QC process determined that the data quality on several lines was inadequate and they were re-surveyed at the time. Two partial lines were later determined to have faulty GPS positioning and were removed, causing a small gap in the final coverage.

The analytic signal (total magnetic gradient) map of the landfill area (Figure 1) shows a very clear magnetic signature in the known landfill areas with only a few sporadic magnetic anomalies interspersed. The correspondence between the mapped wells and most boundaries of the landfill areas with the locations indicated by the magnetic data is excellent.

The homogenous background signature is an indication that native soils have a very low magnetic signature, as would be anticipated from silts, sands, and non-magnetic clays. Any magnetic minerals in the gravels are apparently sparse, or they occur at depths that would cause only small anomalies with our data acquisition parameters. The EM-61 data (not shown here) that were acquired over a southeast quadrant within the grid compared favorably with the magnetic results.

\section{Resistivity Surveys}

Multielectrode resistivity data were acquired at the Camp Roberts landfill area along survey lines designated A-F (Figure 1) and a single deeper sounding that included line $\mathrm{E}$ and $\mathrm{F}$. Data were collected using a 28-electrode Sting/Swift resistivity system and inverted with the program Res2Dinv. For lines A-F, we used an electrode spacing of 19.7 with dipole-dipole configuration.

Line A was over undisturbed ground. Line B straddled the boundary between the undisturbed area and the waste area as delineated by the magnetic data. Line $\mathrm{C}$ is almost entirely within the waste area. The extent of the burial area is clear and the boundary is quite sharp. With the exception of monitoring wells and occasional scrap metal, there were almost no magnetic anomalies along resistivity line $\mathrm{B}$, whereas line $\mathrm{C}$ is clearly over the burial ground.

Lines A-C are collinear, and combine to form a single transect that ran roughly N-S from the top of the hill down to the bottom, across the road, and across the southern disposal area. 
The OhmMapper is a resistivity system that is designed to collect resistivity data continuously along a profile. The transmitter and receiver are capacitively coupled to the ground, so there is no need to hammer electrodes into the ground. The system collects data in a dipole-dipole configuration, so by changing the separation between the transmitter and receiver the depth of investigation can be varied. OhmMapper data were collected along the length of profiles B and C, and over a quadrant within the grid ("Block 15").

The OhmMapper collects makes tightly spaced measurements along the profile (roughly $1.5 \mathrm{ft}$ spacing at a normal walking speed), but the profile must be repeated using different transmitter-receiver separations to build up a depth section. Data were collected data along the combined B-C profile using $10 \mathrm{~m}$ transmitter and receiver dipoles, with separations between the transmitter and receiver of 16.4, 24.6, 32.8, 41.0, and $49.2 \mathrm{ft}$.

One of the principal advantages of the OhmMapper is that by capacitively coupling with the ground the system can collect resistivity data in areas where the near surface is extremely resistive. Such areas occur in northern Canada where the permafrost layer makes it virtually impossible to make good electrical contact with the ground using conventional resistivity systems. Conversely, in regions where the near surface is extremely conductive, as was the case at Camp Roberts, the capacitive coupling of the OhmMapper provides little signal penetration and the resulting data were noisy. Inversion of the OhmMapper data for line B-C (Figures 2 and 3) was accomplished using the same software (Res2Dinv) as for the Sting/Swift resistivity data.

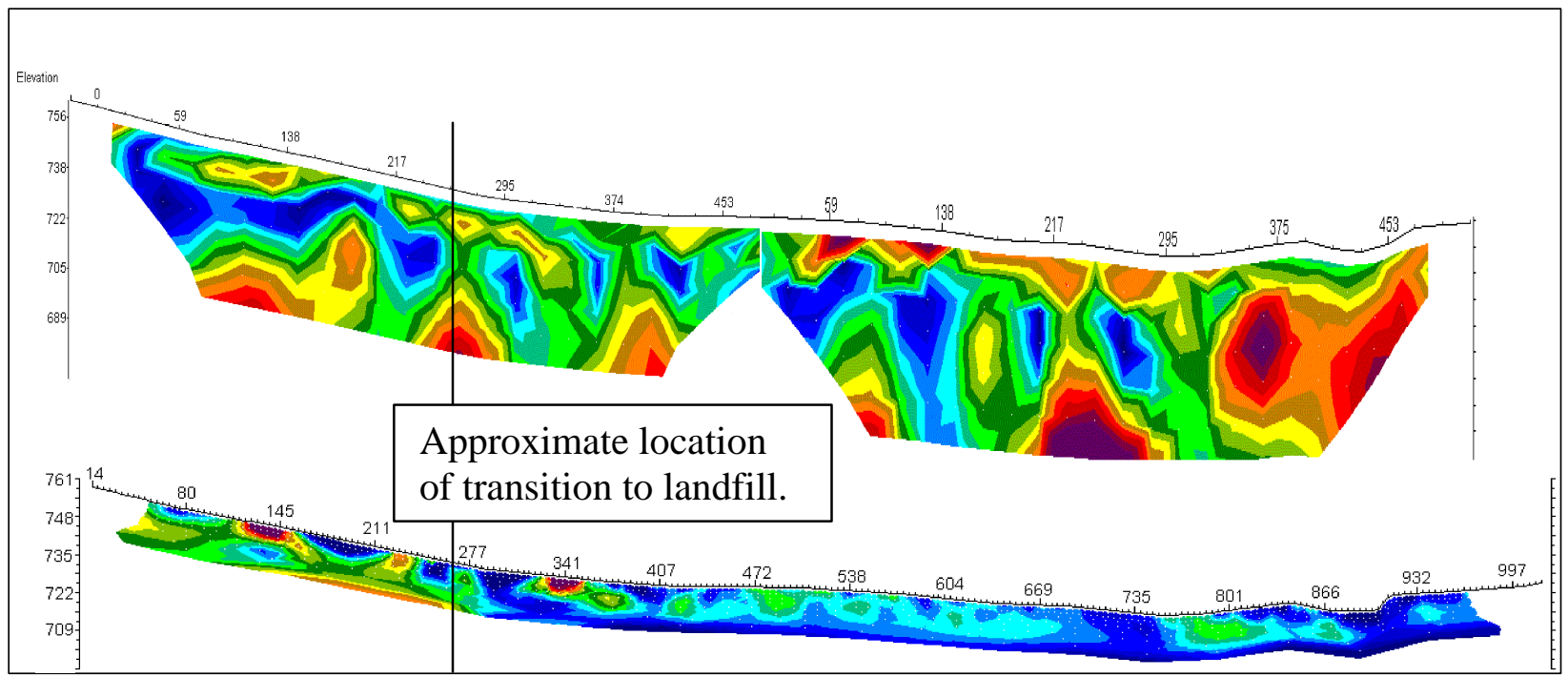

Figure 2. Scaled, stacked section, comparing the Sting/Swift results (top) with the OhmMapper results (bottom) for Lines B (left) and C (right). The Sting/Swift results show a very conductive shallow layer (shown in blue) that is continuous from 0-270 ft starting from the north (left) end of line A. This continuous layer is seen in all lines not over the landfill. The disruption of this layer coincides with the start of the southern landfill as seen in the magnetic data (Figure 1). The OhmMapper resistivity section does not show identical resistivity values, although it does show a change in the character of the resistivity section over the landfill. Both instruments show that the soil is extremely conductive, implying that metallic waste canisters may not be directly detectable with resistivity, but only indirectly through disrupted soil horizons. 


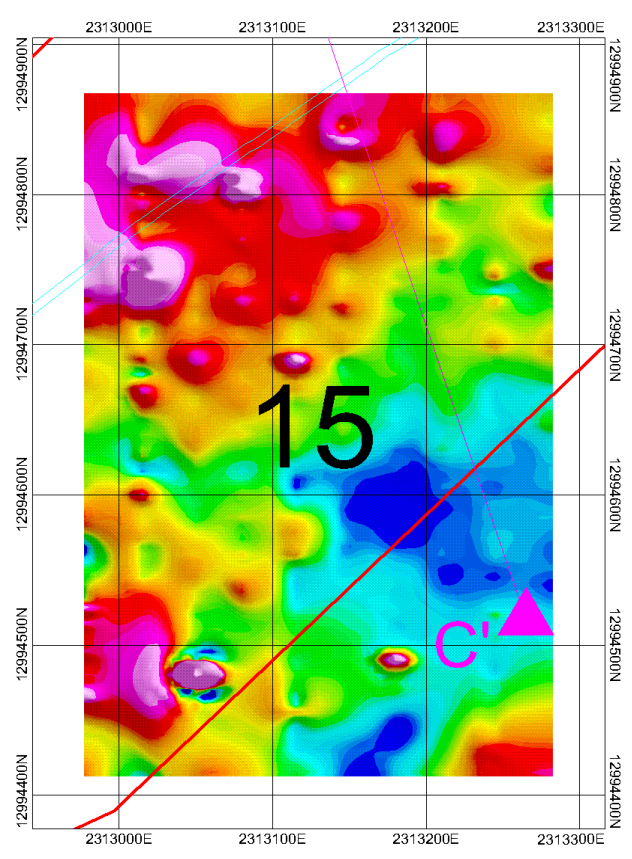

Ohm_Mapper 10m Dipole
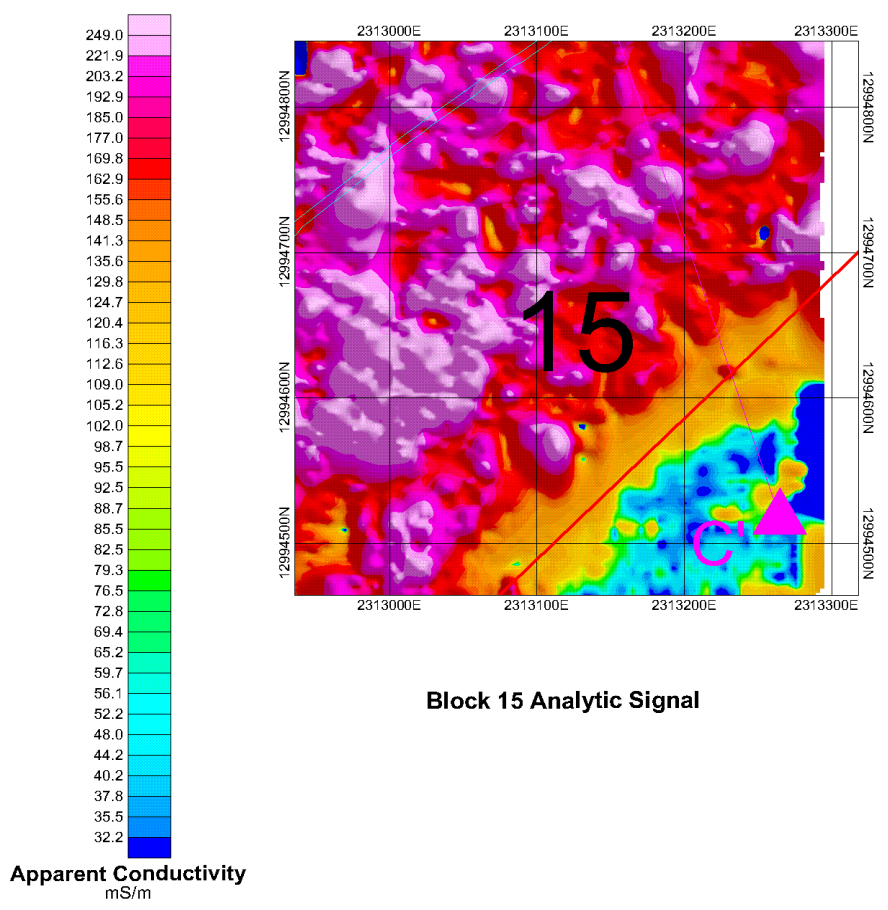

Block 15 Analytic Signal

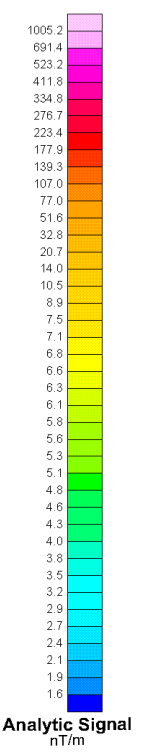

Figure 3. The OhmMapper data (left) and the magnetic analytic signal (right) show a similar pattern, although the magnetic data more clearly delineates the southern boundary of the burial ground (red line). The blue lines show the edges of the dirt road passing through Block 15, and the magenta line shows where profile line $\mathrm{C}$ crosses Block 15. Note that the OhmMapper data covers an area that is slight larger in the N-S direction and slight smaller in the E-W direction than the actual extent of Block 15 (shown in the magnetic data). Coordinates are UTM (ft).

\section{Multielectrode Resistivity Data Interpretation}

It is important to note that the inversion process that translates raw resistivity data into a resistivity cross section is non-unique. The inversion program chooses the smoothest, least heterogeneous, solution. This solves the mathematical problem of non-uniqueness, but produces a slightly blurred image of the actual geology. Abrupt transitions between layers become gradational transitions in the resistivity section.

Second, the data are collected along a line and inverted assuming two-dimensional geologic structure. This assumption is reasonable for a layered earth, or for dipping layers if the data are collected perpendicular to strike, but works less well over localized three-dimensional targets such as buried metal objects. The resistivity data will still show the target, but the dimensions will not be correct. 
In the Line $\mathrm{B} / \mathrm{C}$ combined Sting results, we notice first that the entire section has very low resistivity values - all less than $200 \mathrm{ohm}-\mathrm{m}$. We believe that this is because of the high clay content of the soil, and the presence of evaporites (salts). The drilling logs for the area wells refer to the local Paso Robles Formation as, "silty clay, dark to moderate yellowish brown, stiff non-plastic, dry to moist, with fine- to medium-grained sand, friable, caliche or gypsum along fracture openings." Clay has a low electrical resistivity, and if the pore water is saline, the resistivity will be lower still.

Line B enters into the southern disposal area (inactive) at the south end. The resistivity data show layering that appears to be disrupted at the south end or near the middle of the line (see dashed line on Figure 2), probably because of the landfill excavation and fill. Evaporites may explain the layering. It rained in the weeks preceding our survey, but was dry during our fieldwork. The surface probably dried out, creating a thin resistive zone. Beneath this there is a very low resistivity layer $(<10 \mathrm{ohm}-\mathrm{m})$ that probably corresponds to moist, salty clay. The resistivity increases again below about $33 \mathrm{ft}$. This could be either a moisture change or a lithology change. It is not clear that the metal within the landfill can be distinguished in the resistivity data because the host material already has a very low resistivity. The differences between an extremely good conductor (salty clay) and a near-perfect one (metal) are very subtle.

It is unclear whether the resistivity data can be used to determine the depth of the fill. The disruption of the layering appears to extend to the full depth of the cross section (roughly 50 $\mathrm{ft}$ ); it seems unlikely that material was buried this deep.

Line $\mathrm{C}$, which lies almost entirely within the southern disposal area, shows the same disrupted layering (Figure 2). Interestingly, the very southern end of line $\mathrm{C}$ extends beyond the south end of the burial ground according to the magnetic data, yet the near surface conductive layer is still missing in the resistivity data. In fact, that portion of the line is relatively resistive. The question is whether the magnetic data shows the true southern boundary of the burial ground and there is simply no conductive soil layer present, or the whether burial ground extends further but has no ferrous metal buried further south, and consequently no magnetic anomaly.

Preliminary processing of the resistivity data shows good agreement with the magnetic data. The burial ground shows up as a disruption of the lithologic layering. However, the lowresistivity soils in this area make it difficult to detect buried metal targets. 


\section{OhmMapper Data Interpretation}

The results show about $13 \mathrm{ft}$ of penetration (Figure 2), and the same highly conductive near-surface layer as in the Sting/Swift data. Interestingly, the OhmMapper appears to show the transition to the burial ground, which occurs near the base of the hill as shown by the dashed line in Figure 2, as a change to an even higher conductivity. This was not the case with the Sting/Swift, suggesting that the OhmMapper is more sensitive to buried metal than DC resistivity, or that the because the OhmMapper was sensitive to only upper first four meters of the subsurface, buried metal had a proportionally larger effect on the resistivity data.

The OhmMapper results for Block 15 also demonstrates the sensitivity of the OhmMapper to the buried metal within the boundary of the old landfill (Figure 3). The southwest corner of Block 15 extends beyond the southern boundary of the landfill, and the OhmMapper data show a corresponding decrease in conductivity in the southeast corner.

The OhmMapper data in Figure 3 have been plotted as conductivity values, the reciprocal of resistivity, to make it easier to compare the results with the magnetic analytic signal results for Block 15. We expected conductivity to increase where magnetic field strength increased, and this is shown to be the case when we compare the OhmMapper results to the magnetic analytic signal in Figure 3. Note that this is only a qualitative comparison because the two instruments, the OhmMapper and the magnetometer, are responding to two different physical properties, electrical conductivity and magnetic susceptibility respectively. Although we expect both to be greater over buried metal, the presence of evaporates in the soil has a large influence on the conductivity, but none on the magnetic response.

Although the conductive soils present in the landfill area limited the penetration of the OhmMapper and increased the noise levels, the OhmMapper still provided interesting results. The horizontal resolution was superior to the Sting/Swift multielectrode resistivity system because of the tightly spaced samples (1.6 ft vs. $19.6 \mathrm{ft}$ for the Sting), but penetration was worse (13 ft vs. $80 \mathrm{ft}$ for the Sting).

The OhmMapper proved far superior to the Sting/Swift as a rapid profiling tool. Although the magnetic data were superior for delineating the boundary of the landfill, the OhmMapper performed adequately, and would work well for burial grounds containing only non-magnetic targets such as asbestos, or fiberglass tanks, where the magnetometer would not. The demonstration, although covering only a limited area, successfully highlights the strengths and weaknesses of the OhmMapper system, keeping in mind that the system would have performed even better in a more electrically resistive environment. 


\section{Seismic Refraction}

Seismic refraction data were acquired on 6 profile lines, shown as A, B, C, D, E, and G on Figure 1. The data were acquired with a Bison Elastic Wave Generator II (EWG) source, 48 Input/Output Model SM-24/UB $10 \mathrm{~Hz}$ geophones, and recorded with a Geometrics Strataview portable seismograph. The geophones were spaced at $10 \mathrm{-ft}$ intervals. Data were acquired at source (shot) intervals of 30-ft within the geophone spread, and at offsets of 10,100, 200, and $300 \mathrm{ft}$ from each end of the spreads.

Selected shots were used to build velocity profiles for each line using the SIP family of routines (Rimrock Geophysics, 1995). The SIPT-2 code allows co-processing of up to 7 shots for each geophone spread. First arrivals were picked using the SIPIK code. Picking was difficult with the Roberts data because the first arrivals have very low frequency content, and thus are "emergent" (the amplitude builds slowly, rather than abruptly). These attributes of the first breaks result in a higher likelihood of having a few milliseconds of error in the selected arrival times, and can result in a final model that is less precise. Once first breaks were selected, they were incorporated into a data file for each profile line, using the SIPIN and SIPEDT codes. The data file includes precise positions for each geophone and shot point, and all of the first arrival picks. Each pick was assigned to a specific subsurface layer in the data file. For the Camp Roberts data sets, this was more difficult than for some sites because the data indicate that velocities increase gradationally, rather than abruptly, with depth. SIPT-2 processing assumes that there are discrete layers that are laterally continuous and have constant velocity. Thus the layers that we selected in processing these data are an approximation that assumes constant velocity layers. The cross-section that was determined for Lines B and C, based on analysis with the SIP software is shown in Figure 4.

The data from Lines B and C were also analyzed with the RAYFRACT software. The RAYFRACT code is one of several recent tomographic inversion codes for seismic refraction data. The results of this analysis is shown in Figure 5 shows the result of an inversion of the data for Lines $\mathrm{B}$ and $\mathrm{C}$ that has been parameterized to enhance near-surface features. As a consequence of this selection of inversion parameters, deeper structures are imaged with more distortion. 


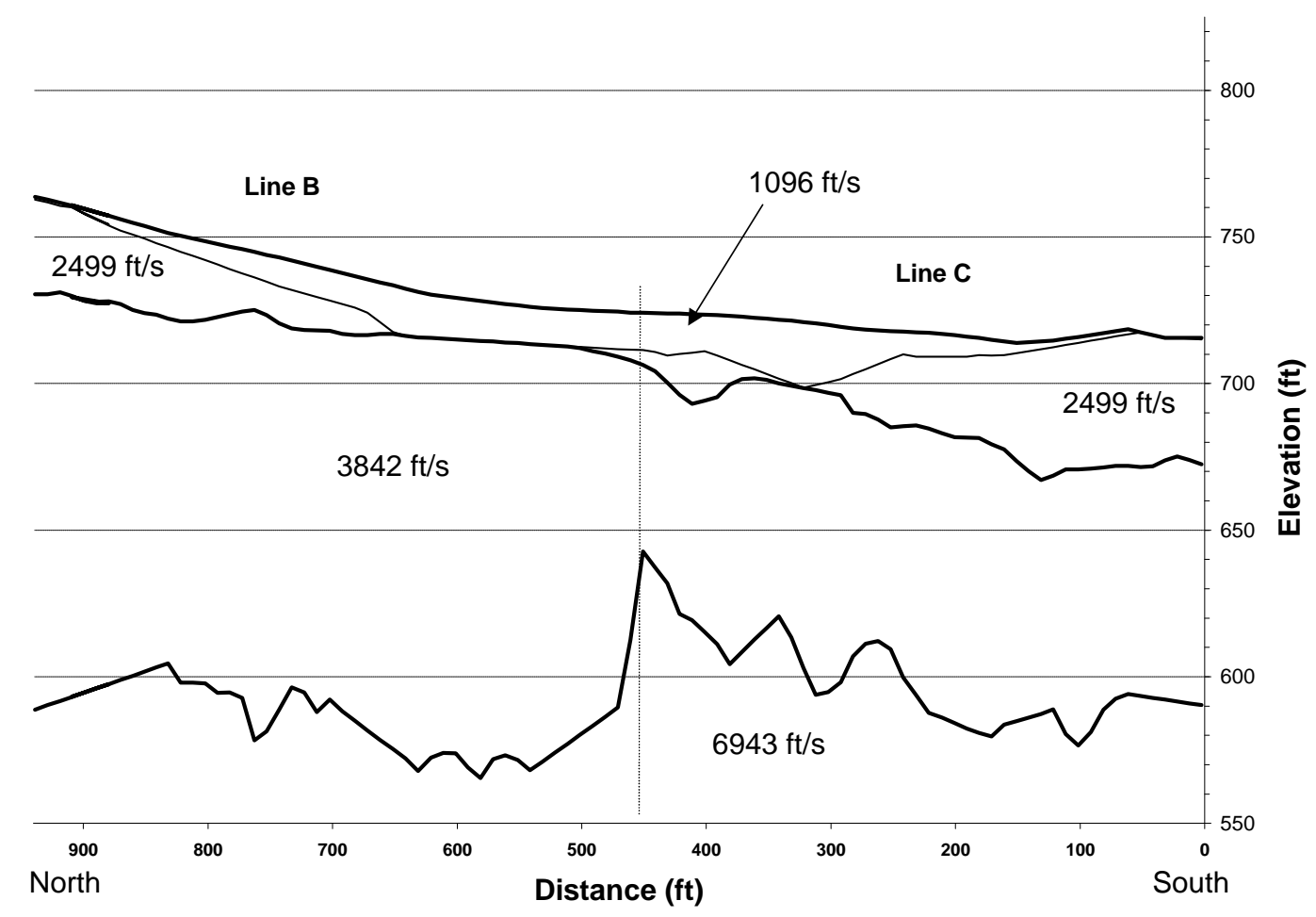

Figure 4. Time-intercept (SIP) results for Lines B and C.

\section{Seismic Data Interpretation}

The time-intercept seismic refraction model for Lines B and C (Figure 4) shows a surface layer of variable thickness and low velocity, presumably associated with dry, unconsolidated sediments. The two underlying layers (2499 ft/s and $3842 \mathrm{ft} / \mathrm{s}$ ) are not clearly differentiated in the data, and thus the contact between these two layers should be treated as a velocity contour in a gradational layer, rather than as an interface between two distinct units. The thickening and thinning of Layer 2 on Line $\mathrm{C}$ is coincident with the mapped boundary of the landfill (Figure 1), and is typical of the manner in which such features appear when layered models are used to represent seismic refraction measurements. The thickening and thinning of Layer 2 on Line $\mathrm{C}$ may cause the sinusoidal disruption of the Layer 3/ Layer 4 contact beneath Line $\mathrm{C}$, and an abrupt depth change for that interface where Line B and Line C meet (470 feet distance, $500 \mathrm{ft}$ elevation on Figure 4). The tops of Layers 3 and 4 are much more continuous laterally on Lines A (not shown) and B, indicating that the near surface is less disturbed. Layer 4 varies between about 570 and $610 \mathrm{ft}$ elevation while Layer 4 is flatter with an elevation of about $730 \mathrm{ft}$ at the north end and about $710 \mathrm{ft}$ at the south end. 


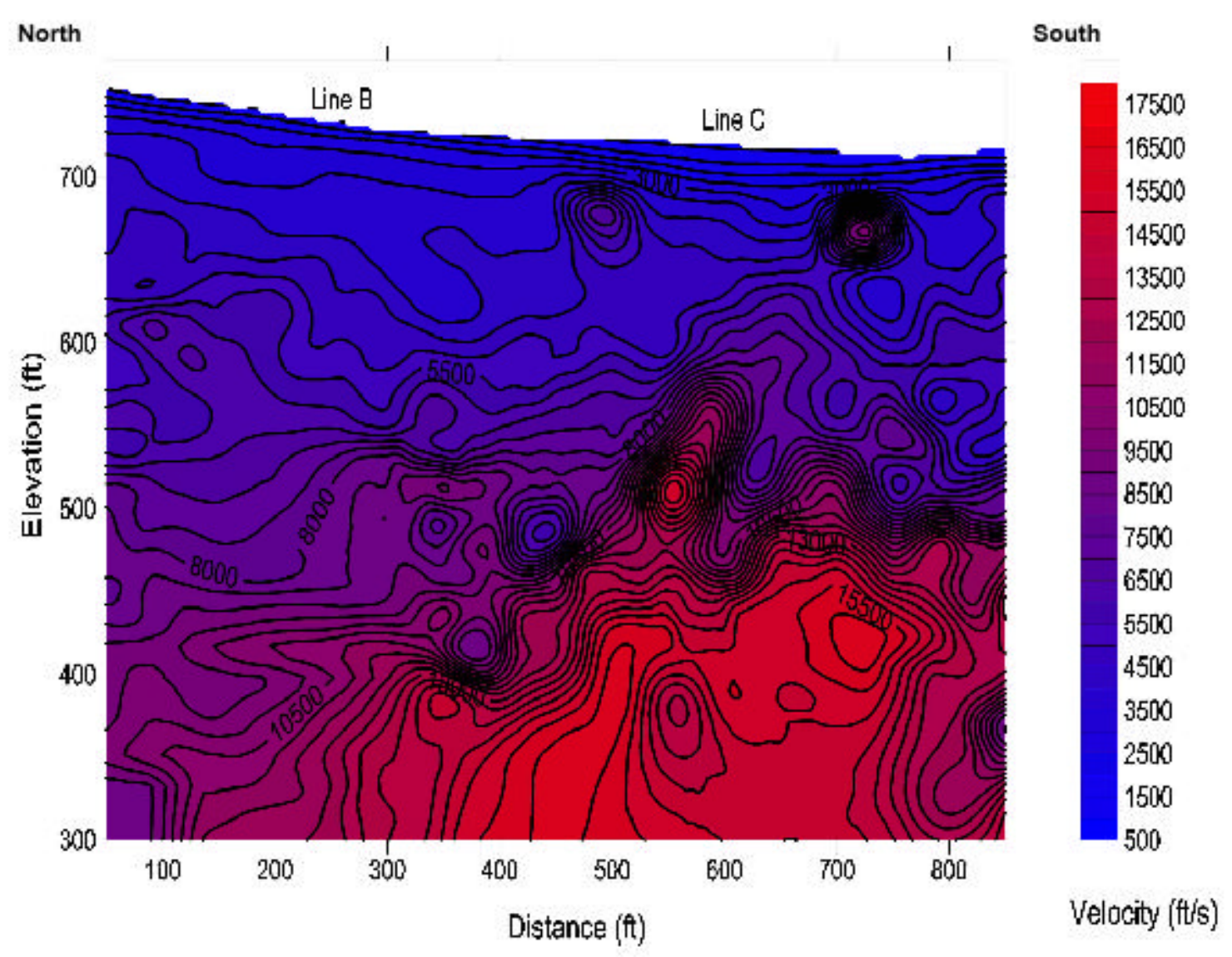

Figure 5. RAYFRACT inversion result for Lines B and C.

The RAYFRACT tomographic image for Lines B and C (Figure 5) appears to provide a more reliable representation of the subsurface. The velocity gradient (continuous increase in velocity with depth rather than abrupt layer changes) is apparent in this image, but the gradient is not constant over the length of the section, indicating significant lateral heterogeneity. High velocity zones at 500 and $725 \mathrm{ft}$ (distance) and about $50 \mathrm{ft}$ beneath the surface correspond well with the northern and southern boundaries of the waste areas (Figure 1). The depths of the zones are probably too large, and may indicate that the receiver spacing (10 feet) is too large for the inversion to accurately resolve these near-surface features. A steep velocity gradient occurs along an irregular surface at about $500 \mathrm{ft}$ altitude, particularly on the southern half (Line C) of the section. The structure on this surface may be an artifact caused by the disturbed near surface zone, or it could represent an irregular bedrock surface that underlies the site. A similar feature appears at shallower depths on the delay-time model (Figure 4). The steep northward gradient in the water table that was discussed in the Introduction may be related to this velocity structure. Deeper portions of the image should be treated with caution, as they are not well constrained by this inversion, particularly near the northern and southern margins of the image. It is noteworthy that no clear boundary corresponds with the mapped water table depth, as was noted earlier for the time-intercept section for these lines. 
The tomographic result for Lines B and C demonstrates that a tomographic solution is much more appropriate to the Camp Roberts data than the time-intercept solution. Not only does it provide a credible representation of the trench area, but it also shows the velocity gradient and absence of layering that were problematic in the time-intercept results. The interpretations of time-intercept results for other lines should be treated with caution with the tomographic results in mind.

\section{Landfill boundaries}

\section{Conclusions}

The magnetic results clearly define the boundaries of the active and historic landfills, and show no evidence of trenches or buried wastes between them. The landfill boundaries that are defined in map view by the magnetic data are supported in profile by the seismic refraction data and multielectrode resistivity data. The seismic data are most effective in identifying trench locations when a tomographic inversion is used, instead of a conventional delay-time approach to interpretation. This shows a localized high-velocity zone that coincides with the trench boundaries that are defined by the magnetic data. The multielectrode resistivity data show a disruption of layering where trenching has occurred.

\section{Heterogeneity}

Both the seismic data and the multielectrode resistivity data provide evidence that the shallow geology is laterally discontinuous and heterogeneous. This could include zones of caliche, perched water, and/or facies changes associated with fluvial deposition that would include (at a minimum) sandstones, mudstones, and conglomerates. Such a geologic setting demonstrates the limitations of geophysical analysis methods that assume lateral continuity and which disallow gradational changes in physical properties. In the case of the seismic data, the geologic setting is much better suited for processing with a tomographic inversion approach than a conventional delay-time method. The high electrical conductivity of the near surface imposed limitations on the penetration depth of both the OhmMapper and multielectrode resistivity systems. The multielectrode system was better suited for penetrating this zone than was the OhmMapper. 


\section{Acknowledgements}

We thank the Army Environmental Center and Camp Roberts Environmental Office staff for their assistance in completing the work. Guy Romine, of the National Guard Bureau in Los Alamitos CA, provided extensive field assistance in addition to insight on site history, issues, and procedures. Field assistance was also provided by Barry Kinsall of ORNL, Jon Cunningham and Don Rock of Lawrence Livermore National Laboratory, and Frank Gardner and John Zutman of the ORNL Grand Junction Office.

Oak Ridge National Laboratory is managed by UT-Battelle, LLC for the U. S. Department of Energy under contract DE-AC05-00OR22725. The submitted manuscript has been authored by a contractor of the U. S. Government. Accordingly, the U. S. Government retains a nonexclusive, royalty-free license to publish or reproduce the published form of this contribution, or allow others to do so, for U. S. Government purposes.

\section{References}

1 EMCON Associates, 1990, Water Solid Waste Assessment Test Interim Report, Camp Roberts Sanitary Landfill, San Luis Obispo County, California, 23 pp., June 1990.

2 Environmental Science Associates, Inc, 1989, Geologic map of Camp Roberts, California, Scale: 1:25,000, derived from Camp Roberts Environmental Management Analysis Plan, February 1989.

3 Geosystem Consultants, Inc., 1998, Groundwater and vadose zone monitoring, third quarter 1998, Solid waste disposal facilities, Camp Roberts, California, provided as a PDF file on CD-ROM.

$4 \quad$ Rimrock Geophysics, 1995, User's guide to SIPx programs, 1995.

5 Smith, Gardner, and Dunne, Inc., 1989, Water Quality Solid Waste Assessment Test, Camp Roberts Sanitary Landfill, San Luis Obispo County, California, June 1989. 